\title{
Risk factor management in diabetic and non-diabetic patients with coronary heart disease. Findings from the EUROASPIRE I and II surveys
}

\author{
K. Pyörälä ${ }^{1}$ S. Lehto ${ }^{1}$ D. De Bacquer ${ }^{2}$ J. De Sutter ${ }^{2} \cdot$ S. Sans ${ }^{3} \cdot$ U. Keil ${ }^{4}$ D. Wood $^{5}$ G. De Backer ${ }^{2}$ \\ the EUROASPIRE I and II Groups* \\ ${ }^{1}$ Department of Medicine, Kuopio University Hospital, Kuopio, Finland \\ ${ }^{2}$ Department of Public Health, University of Ghent, Ghent, Belgium \\ ${ }^{3}$ Department of Health and Social Security, Institute of Health Studies, Barcelona, Spain \\ ${ }^{4}$ Institute of Epidemiology and Social Medicine, University of Münster, Münster, Germany \\ ${ }^{5}$ Cardiovascular Medicine, National Heart and Lung Institute, Imperial College School of Medicine at Charing Cross Campus, \\ London, UK
}

\begin{abstract}
Aims/hypothesis. We examined risk factor management in diabetic and non-diabetic patients with CHD based on data from EUROASPIRE surveys.

Methods. Consecutive CHD patients aged 70 years or younger were interviewed and examined at least 6 months after hospitalisation for a revascularisation procedure or acute myocardial infarction or ischaemia. Of these patients, 3569 were from the EUROASPIRE I study, undertaken from 1995 to 1996 in nine countries, and 5556 were from the EUROASPIRE II study, conducted between 1999 and 2000 in 15 countries.

Results. In EUROASPIRE I and II 18\% and 20\% of CHD patients respectively had been previously diagnosed with diabetes. Fasting glucose screening raised the prevalence of diabetes in EUROASPIRE II to $28 \%$. In EUROSPIRE II the prevalence of risk factors (known diabetic/non-diabetic) was: current smoking $17 \% / 22 \%(p=0.25)$; obesity (BMI $\left.\geq 30 \mathrm{~kg} / \mathrm{m}^{2}\right) 43 \% /$ $29 \%(p<0.001)$; raised blood pressure $(\geq 140 / 90 \mathrm{~mm}$
\end{abstract}

$\mathrm{Hg}) 57 \% / 49 \%(p<0.001)$; and elevated total cholesterol ( $\geq 5.0 \mathrm{mmol} / \mathrm{l}) 55 \% / 59 \%(p<0.001)$. The proportion of users of cardiovascular medication was: antiplatelet drugs $83 \% / 86 \%$ (NS); beta-blockers 62\%/63\% (NS); ACE inhibitors $49 \% / 35 \%(p<0.001)$; and lipid-lowering drugs $62 \% / 61 \%$ (NS). A comparison of both studies showed that for diabetic and non-diabetic patients the prevalence of smoking had increased somewhat and that the prevalence of obesity had increased clearly. There was no improvement in blood pressure control, but cholesterol control had improved, mainly explained by the increased use of lipid-lowering drugs.

Conclusions/interpretation. These European surveys show a high prevalence of adverse lifestyles and modifiable risk factors among diabetic and non-diabetic patients with CHD. The risk factor status was more adverse in diabetic patients.

Keywords Blood pressure - Cardiovascular agents · Cholesterol $\cdot$ Coronary disease $\cdot$ Diabetes mellitus . Obesity $\cdot$ Risk factors $\cdot$ Smoking
Received: 21 November 2003 / Accepted: 17 March 2004

Published online: 2 July 2004

C) Springer-Verlag 2004

K. Pyörälä (๘)

Department of Medicine, Kuopio University Hospital,

P.O. Box 1777, 70211 Kuopio, Finland

E-mail: kalevi.pyorala@uku.fi

Tel.: +358-17-171259, Fax: +358-17-173993

* Investigators and centres participating in EUROASPIRE I and II are listed in references [31] and [32]

\section{Introduction}

People with diabetes have a markedly increased risk of CHD and other forms of atherosclerotic disease [1, $2,3,4,5,6]$. This applies to both Type 1 (insulin-dependent) and Type 2 (non-insulin-dependent) diabetes,

Abbreviations: AMI, acute myocardial infarction $\cdot \mathrm{CABG}$, coronary artery bypass grafting · EUROASPIRE, European Action on Secondary Prevention through Intervention to Reduce Events · FPG, fasting plasma glucose · IGR, impaired glucose regulation PTCA, percutaneous transluminal coronary angioplasty 
but because Type 2 diabetes accounts for over $90 \%$ of all cases of diabetes, the majority of clinical manifestations of CHD and other atherosclerotic diseases in people with diabetes occur in patients with Type 2 diabetes. Currently, about $20 \%$ of patients with clinically established CHD have been previously diagnosed with diabetes $[7,8,9,10,11]$, and among patients with CHD the prevalence of undiagnosed diabetes is also high [12]. The long-term prognosis after a myocardial infarction or an episode of unstable angina is worse in diabetic than in non-diabetic patients $[7,8$, $9,10]$ and the same applies to the prognosis after coronary artery bypass grafting [13] or percutaneous coronary intervention [11].

Evidence from clinical trials indicates that the relative reduction in CHD risk resulting from risk factor interventions is similar in diabetic and non-diabetic individuals, but because of their higher absolute CHD risk the absolute benefit is even greater in diabetic individuals. Such evidence is available on lipid-lowering drugs $[14,15,16,17,18]$, blood-pressure-lowering drugs $[19,20,21]$, antiplatelet drugs [22], betablockers [23] and ACE-inhibitors [24, 25, 26]. Trial evidence on the effect of glycaemic control on the risk of primary and recurrent CHD events in diabetic subjects still remains scarce. The UK Prospective Diabetes Study showed, however, that in Type 2 diabetic patients improved glycaemic control reduced the risk of myocardial infarction [27]. Although only observational but no specific trial evidence is available on the benefits of healthy lifestyles (prudent diet, avoidance of overweight, regular physical activity, and avoidance of smoking) for the reduction of CHD risk in diabetic people, such measures are presumably even more important for people with diabetes than for nondiabetic individuals. Thus, there is a great potential for preventive practice in diabetic patients in general, and particularly in those with CHD.

Patients with clinically established CHD are defined as the highest priority in the Joint European Societies' guidelines on the prevention of CHD, which were published in 1994, 1998 and 2003 [28, 29, 30 ] and clearly emphasise the high-risk status of diabetic patients. Two surveys about the actual practice of secondary prevention of CHD and its progress have been published. The first was EUROASPIRE (European Action on Secondary Prevention through Intervention to Reduce Events) I, conducted in nine countries (the Czech Republic, Finland, France, Germany, Hungary, Italy, the Netherlands, Slovenia and Spain) from 1995 to 1996 [31]. The second, EUROASPIRE II, covered 15 countries (the previous nine plus Belgium, Greece, Ireland, Poland, Sweden and UK) and was conducted from 1999 to 2000 [32]. Drawing on these studies, this article examines and compares risk factor management, including the use of prophylactic cardiovascular drugs, in diabetic and non-diabetic patients with CHD. The main emphasis will be on find- ings from EUROASPIRE II, but the findings from EUROASPIRE I and II will also be compared to demonstrate the trends in preventive practice.

\section{Subjects and methods}

Study populations. The study populations of EUROASPIRE I and II have been described in previous publications [31, 32]. Briefly, within each country, one or several geographical areas with a defined population were selected and hospitals serving that population were identified. Within each hospital, consecutive patients of both sexes, who were aged 70 years or less and had been hospitalised for the treatment of CHD, were identified retrospectively using the following hierarchical category of diagnoses: (i) coronary artery bypass grafting (CABG); (ii) percutaneous transluminal coronary angioplasty (PTCA); (iii) acute myocardial infarction (AMI); and (iv) acute myocardial ischaemia without infarction. In each country, the aim was to obtain approximately equal numbers of patients from each of these four diagnostic categories and a total of about 400 patients for interview and risk factor assessment at least 6 months after hospitalisation for the index event had occurred.

In EUROASPIRE I 4863 patients fulfilling the inclusion criteria were identified, 4576 patients were contacted and still alive, and $3569(78 \%)$ were interviewed and examined. In EUROASPIRE II the corresponding numbers were: 8181, 7310 and $5556(76 \%)$. In both surveys the median time between index event and interview was 1.4 years (interquartile ranges: $1.1-2.0$ years and 1.1-1.9 years). All participants gave informed consent.

Methods. The study protocols and methods applied in EUROASPIRE I and II have been previously described [31, 32, 33]. The patient interview and examination included: personal and demographic details, CHD and diabetes history, information on lifestyle advice given by health professionals, use of cardiovascular drugs, assessment of smoking status (validated by measurement of breath carbon monoxide), measurement of height, weight and waist circumference, calculation of BMI $\left(\mathrm{kg} / \mathrm{m}^{2}\right)$, blood pressure measurement, and measurement of plasma lipid concentrations by a central laboratory, with arrangements described previously [31, 32, 33]. In EUROASPIRE II plasma glucose was measured from samples separated from lithium-heparin venous blood and sent frozen to the central laboratory, where values were determined using the hexokinase method on a Bayer Axon analyser (Bayer, Leverkusen, Germany), with a coefficient of variation of $2.8 \%$.

The diagnosis of known diabetes at interview was based on a history of diabetes diagnosed by a physician. In EUROASPIRE II the criteria given in the 1999 Report of the World Health Organization Consultation [34] were used in patients without a history of diabetes to diagnose the two categories of impaired glucose regulation (IGR): (i) diabetes = fasting plasma glucose $(\mathrm{FPG}) \geq 7.0 \mathrm{mmol} / \mathrm{l}$; and (ii) impaired fasting glycaemia $=F P G \geq 6.1 \mathrm{mmol} / 1$ but $<7.0 \mathrm{mmol} / 1$.

Statistical analyses. Descriptive statistics were used to illustrate the demographic characteristics and to estimate the prevalence of risk factors and the use cardiovascular drugs. Age distributions were compared using the non-parametric MannWhitney test and distributions of continuous risk factor variables using analysis of covariance modelling, adjusting for age, sex, diagnostic category and centre. In these models $p$ values were corrected with the Dunnett-Hsu procedure for multiple testing against the reference group [35]. Lipid variables 
were log-transformed in the statistical analyses. Differences in binary outcomes, adjusting for age, sex, diagnostic category and centre, were evaluated by logistic regression modelling with $p$ values based on the Wald chisquare statistic. Calculation of $95 \%$ CIs for differences in frequency estimates between EUROASPIRE I and EUROASPIRE II was done according to the Newcombe-Wilson hybrid score method [36]. A logistic model including an interaction term between diabetic status and survey was used to examine whether the between-survey differences in diabetic and non-diabetic patients actually constituted a difference. A $p$ value of less than 0.05 was considered statistically significant.

\section{Results}

Prevalence, mode of treatment and glycaemic control of diabetes

In EUROASPIRE I, 641 (18.0\%) of the 3569 interviewed patients had a history of previously diagnosed diabetes. The figure for EUROASPIRE II was 1086 $(19.6 \%)$ of the 5556 interviewed patients. Table 1 shows the prevalence of known diabetes by centre, diagnostic category, sex and age. In both surveys the prevalence of diabetes was higher in patients who had undergone CABG than in other diagnostic categories. It was also higher in women than in men, and in patients older than 60 years. All the results reported in this article are based on data from the whole study populations combining data from different centres, diagnostic categories and data for men and women.

In EUROASPIRE II, $876(19.5 \%)$ of the 4489 patients with FPG measurements after a fast of at least 6 hours had known diabetes. In addition, 383 patients $(8.5 \%)$ had undiagnosed diabetes (FPG $\geq 7.0 \mathrm{mmol} / \mathrm{l}$ ), raising the total prevalence of diabetes to $28.0 \%$. The number of patients with impaired fasting glycaemia (FPG $\geq 6.1 \mathrm{mmol} / \mathrm{l}$ but $<7.0 \mathrm{mmol} / \mathrm{l}$ ) was $850(18.9 \%$ ). When these were included, the prevalence of IGR was as high as $46.9 \%$.

Of the 641 patients with known diabetes in EUROASPIRE I, 39.5\% were treated with diet only, $39.9 \%$ with oral hypoglycaemic drugs and $20.6 \%$ with insulin (including patients receiving insulin plus oral hypoglycaemic drugs). In EUROASPIRE II, information on the mode of treatment was available for 1072 patients with known diabetes. Of them, $24.0 \%$ were treated with diet only, $50.3 \%$ with oral hypoglycaemic drugs and $25.8 \%$ with insulin.

In EUROASPIRE II, FPG measurements were available on 823 patients with known diabetes. In $12.5 \%$ of them FPG was $6.0 \mathrm{mmol} / \mathrm{l}$ or lower, in $15.1 \%$ it was 6.0 to $6.9 \mathrm{mmol} / \mathrm{l}$, and in $72.4 \%$ it was $7.0 \mathrm{mmol} / \mathrm{l}$ or higher. There was no significant difference in FPG distribution between insulin-treated $(n=276)$ and non-insulin-treated patients $(n=796$; treated with diet only or with oral hypoglycaemic drugs).
Table 1. Size of study populations and prevalence of known diabetes by centre, diagnostic category, sex and age in EUROASPIRE I and EUROASPIRE II

\begin{tabular}{|c|c|c|c|c|}
\hline & \multicolumn{2}{|c|}{ EUROASPIRE I } & \multicolumn{2}{|c|}{ EUROASPIRE II } \\
\hline & $n$ & $\begin{array}{l}\text { Prevalence } \\
\text { of known } \\
\text { diabetes, } \\
n(\%)\end{array}$ & $n$ & $\begin{array}{l}\text { Prevalence } \\
\text { of known } \\
\text { diabetes, } \\
n(\%)\end{array}$ \\
\hline \multicolumn{5}{|l|}{ Centre $^{a}$} \\
\hline BEL/GHE & & & 260 & $37(14.2)$ \\
\hline $\mathrm{CZE} / \mathrm{PP}$ & 331 & $72(21.8)$ & 410 & $88(21.5)$ \\
\hline FIN/KUO & 415 & $65(15.4)$ & 348 & $65(18.7)$ \\
\hline FRA/LLRT & 396 & $66(16.7)$ & 365 & $100(27.5)$ \\
\hline GER/MÜNS & 392 & $53(13.5)$ & 402 & $54(13.5)$ \\
\hline GRE/ATCI & & & 391 & $83(21.3)$ \\
\hline HUN/BUD & 421 & $112(26.6)$ & 389 & $82(21.1)$ \\
\hline IRE/DUB & & & 345 & $30(8.7)$ \\
\hline ITA/UTV & 425 & $73(17.2)$ & 258 & $56(21.8)$ \\
\hline NET/ROT & 387 & $40(10.3)$ & 357 & $47(13.2)$ \\
\hline POL/CRA & & & 427 & $65(15.2)$ \\
\hline SLO/LJU & 413 & $72(17.4)$ & 446 & $106(23.8)$ \\
\hline SPA/BAR & 389 & $89(22.9)$ & 404 & $142(35.2)$ \\
\hline SWE/MAL & & & 392 & $55(14.0)$ \\
\hline UK/HL & & & 362 & $76(21.0)$ \\
\hline \multicolumn{5}{|c|}{ Diagnostic category } \\
\hline $\mathrm{CABG}$ & 909 & $191(21.0)$ & 1423 & $333(23.4)$ \\
\hline PTCA & 904 & $137(15.2)$ & 1560 & $259(16.6)$ \\
\hline AMI & 930 & $174(18.7)$ & 1462 & 277 (19.0) \\
\hline ISCHAEMIA & 826 & 139 (16.8) & 1111 & 217 (19.6) \\
\hline \multicolumn{5}{|l|}{ Sex } \\
\hline Men & 2717 & $455(16.8)$ & 4237 & 765 (18.1) \\
\hline Women & 852 & $186(21.8)$ & 1319 & $321(24.4)$ \\
\hline \multicolumn{5}{|l|}{ Age } \\
\hline$\leq 60$ years & 1694 & $248(14.6)$ & 2590 & $422(16.3)$ \\
\hline$>60$ years & 1872 & $393(21.0)$ & 2966 & $664(22.4)$ \\
\hline All patients & 3569 & $641(18.0)$ & 5556 & 1086 (19.6) \\
\hline
\end{tabular}

${ }^{\mathrm{a}} \mathrm{BEL} / \mathrm{GHE}=$ Belgium/Ghent; CZE/PP = Czech Republic/ Pilsen, Prague; FIN/KUO = Finland/ Kuopio; FRA/LLRT = France/Lille,Lomme, Roubaix, Tourcoing (Tourcoing not included in EUROASPIRE I); GER/MÜNS = Germany/Münster; GRE/ATCI = Greece/Athens, Thessaloniki, Crete, Ionnanina; HUN/BUD = Hungary/Budapest; IRE/DUB = Ireland/Dublin; ITA/UTV = Italy/Udine, Treviso, Verona (Udine not included in EUROASPIRE II); NET/ROT = The Netherlands/Rotterdam; POL/CRA = Poland/Cracow province; SLO/LJU = Slovenia/Ljubljana; SPA/BAR = Spain/Barcelona and province; SWE $/$ MAL = Sweden $/$ Malmö; UK/HL = United Kingdom $/$ Hull, London. CABG, coronary artery bypass grafting; PTCA, percutaneous transluminal coronary angioplasty; AMI, acute myocardial infarction; ISCHAEMIA, acute myocardial ischaemia without infarction

\section{Findings from EUROASPIRE II}

Risk factors and their control. Table 2 shows the distribution of age and continuous risk factor variables in diabetic and non-diabetic patients at interview. 
Table 2. Distribution of age and continuous risk factor variables in diabetic and non-diabetic patients in EUROASPIRE II

\begin{tabular}{lccc}
\hline & Diabetic, $(n=1086)$ & Non-diabetic, $(n=4464)$ & $p$ value ${ }^{\mathrm{a}}$ \\
\hline Age, years & $62.7(56.4-67.4)$ & $60.4(53.1-66.7)$ & $<0.001$ \\
BMI, kg/m ${ }^{2}$ & $29.1(26.5-32.2)$ & $27.8(25.3-30.4)$ & \\
Waist circumference, cm & & & $<0.001$ \\
Men & $103(97-111)$ & $100(94-107)$ & $<0.001$ \\
Women & $99(92-107)$ & $92(84-100)$ & $<0.001$ \\
Systolic BP, mm Hg & $142.5(127.5-160.0)$ & $136.5(124.0-152.5)$ & $<0.001$ \\
Diastolic BP, mm Hg & $80.0(72.5-88.5)$ & $5.5(75.0-90.0)$ & 0.02 \\
Total cholesterol, mmol/1 & $5.14(4.38-6.03)$ & $1.20(1.02-1.43)$ & $<.03)$ \\
HDL cholesterol, mmol/l & $1.13(0.97-1.35)$ & $1.48(1.09-2.10)$ & $<07$ \\
Triglycerides, mmol/lb & $1.64(1.23-2.39)$ & $3.22(2.60-3.93)$ & $<0.001$ \\
LDL cholesterol, mmol/1 b & $3.18(2.52-3.90)$ & $3.96(3.31-4.76)$ & 0.001 \\
Non-HDL cholesterol, mmol//b & $3.93(3.25-4.82)$ & 0.30 & \\
\hline
\end{tabular}

Data are given in medians and interquartile ranges. a Adjusting for age, sex, diagnostic category and centre, as appropriate.

b Based on results for patients who had fasted for 6 or more hours. BP, blood pressure

Table 3. Prevalence of major risk factors in diabetic and non-diabetic patients in EUROASPIRE II

\begin{tabular}{|c|c|c|c|}
\hline & Diabetic, $(n=1086)$ & Non-diabetic, $(n=4464)$ & $p$ value \\
\hline \multicolumn{4}{|l|}{ Current smoking } \\
\hline Men & $18.7 \%$ & $23.0 \%$ & 0.27 \\
\hline Women & $14.0 \%$ & $18.7 \%$ & 0.64 \\
\hline All patients & $17.3 \%$ & $22.0 \%$ & 0.25 \\
\hline \multicolumn{4}{|l|}{ Overweight/obesity } \\
\hline \multicolumn{4}{|l|}{ Abdominal obesity } \\
\hline Men, waist $\geq 102 \mathrm{~cm}$ & $55.7 \%$ & $44.1 \%$ & $<0.001$ \\
\hline Women, waist $\geq 88 \mathrm{~cm}$ & $85.9 \%$ & $64.2 \%$ & $<0.001$ \\
\hline \multicolumn{4}{|l|}{ Raised BP } \\
\hline$\geq 4.5 \mathrm{mmol} / 1$ & $71.2 \%$ & $77.7 \%$ & $<0.001$ \\
\hline$\geq 5.0 \mathrm{mmol} / 1$ & $54.6 \%$ & $59.2 \%$ & $<0.001$ \\
\hline \multicolumn{4}{|l|}{ Elevated LDL cholesterolb } \\
\hline$\geq 2.5 \mathrm{mmol} / 1$ & $75.4 \%$ & $79.1 \%$ & $<0.001$ \\
\hline$\geq 3.0 \mathrm{mmol} / 1$ & $57.3 \%$ & $59.0 \%$ & 0.009 \\
\hline
\end{tabular}

a Adjusting for age, sex, diagnostic category and centre. ${ }^{\mathrm{b}}$ Based on results for patients who had fasted for 6 hours or more. $\mathrm{BP}$, blood pressure

Diabetic patients were more obese and had higher ystolic but lower diastolic blood pressure than nondiabetic patients. Total and LDL cholesterol and HDL cholesterol were lower, whereas triglycerides were higher in diabetic than in non-diabetic patients. NonHDL cholesterol levels were similar in diabetic and non-diabetic patients. In patients treated with insulin systolic blood pressure was somewhat higher (median $144.5 \mathrm{~mm} \mathrm{Hg}$ vs $141.0 \mathrm{~mm} \mathrm{Hg}$; $p=0.07$ ) and diastolic blood pressure lower (median $78.5 \mathrm{~mm} \mathrm{Hg}$ vs $81.0 \mathrm{~mm} \mathrm{Hg} ; p=0.01$ ) than in patients not treated with insulin. Poor glycaemic control was associated with more severe dyslipidaemia. Thus in diabetic patients with FPG of $6.0 \mathrm{mmol} / \mathrm{l}$ or less, of 6.0 to $6.9 \mathrm{mmol} / \mathrm{l}$, and of $7.0 \mathrm{mmol} / \mathrm{l}$ or more, the median values for HDL cholesterol were 1.16, 1.11 and $1.12(p=0.01)$, and for triglycerides $1.34,1.58$ and $1.75(p<0.001)$ respectively.

Table 3 shows the prevalence of the most important risk factors in diabetic and non-diabetic patients, using the cut-offs given for continuous risk factors in the 1998 Joint European Societies' guidelines, and also 
Table 4. Distribution of age and risk factor variables in patients with known diabetes, undiagnosed diabetes, impaired fasting glycaemia and normoglycaemia in EUROASPIRE II

\begin{tabular}{|c|c|c|c|c|}
\hline & $\begin{array}{l}\text { Known diabetes } \\
(n=876)\end{array}$ & $\begin{array}{l}\text { Undiagnosed diabetes } \\
(n=383)\end{array}$ & $\begin{array}{l}\text { Impaired fasting } \\
\text { glycaemia }(n=850)\end{array}$ & $\begin{array}{l}\text { Normoglycaemia } \\
(n=2380)\end{array}$ \\
\hline Age, years & $62.8(56.4-67.6)$ & $60.4(53.0-66.4)$ & $60.8(54.1-67.1)$ & $60.2(52.7-66.7)$ \\
\hline BMI, $\mathrm{kg} / \mathrm{m}^{2}$ & $29.1^{\mathrm{c}}(26.5-32.2)$ & $29.4^{\mathrm{c}}(26.6-32.3)$ & $28.7^{\mathrm{c}}(26.2-31.1)$ & $27.2(24.8-29.7)$ \\
\hline \multicolumn{5}{|l|}{ Waist circumference, $\mathrm{cm}$} \\
\hline Systolic BP, mm Hg & $143.0^{\mathrm{c}}(128.0-160.5)$ & $139.5^{\mathrm{b}}(127.5-155.5)$ & $139.0^{a}(127.5-152.5)$ & $135.5(123.0-151.5)$ \\
\hline Diastolic BP, mm Hg & $81.0(74.0-90.0)$ & $83.5(75.5-91.5)$ & $83.5^{\mathrm{a}}(76.5-90.0)$ & $82.0(74.5-89.5)$ \\
\hline Total cholesterol, mmol/l & $5.21(4.42-6.09)$ & $5.34(4.63-6.13)$ & $5.48^{\mathrm{c}}(4.65-6.23)$ & $5.19(4.56-5.95)$ \\
\hline HDL cholesterol, mmol/1 & $1.13^{\mathrm{c}}(0.97-1.34)$ & $1.10^{\mathrm{c}}(0.91-1.30)$ & $1.16^{\mathrm{c}}(1.00-1.36)$ & $1.23(1.05-1.47)$ \\
\hline Triglycerides, mmol/l & $1.64^{\mathrm{c}}(1.23-2.39)$ & $2.02^{\mathrm{c}}(1.37-2.94)$ & $1.68^{\mathrm{c}}(1.22-2.39)$ & $1.38(1.02-1.87)$ \\
\hline
\end{tabular}

Data are given in medians and interquartile ranges or frequencies $(\%)$. ${ }^{\mathrm{a}} p<0.05,{ }^{\mathrm{b}} p<0.01,{ }^{\mathrm{c}} p<0.001$ compared with the normoglycaemia group, adjusting for age, sex, diagnostic category and centre, as appropriate. BP, blood pressure

Table 5. Lifestyle advice reported by diabetic and non-diabetic patients in EUROASPIRE II

\begin{tabular}{|c|c|c|c|}
\hline Stop smokingb & $89.2 \%$ & $87.8 \%$ & 0.45 \\
\hline Lose weightc & $73.7 \%$ & $52.5 \%$ & $<0.0001$ \\
\hline Diet to lower cholesterole & $64.5 \%$ & $61.7 \%$ & 0.18 \\
\hline Exercise $^{f}$ & $70.3 \%$ & $65.7 \%$ & 0.19 \\
\hline Participate in cardiac rehabilitation programme $\mathrm{f}^{\mathrm{f}}$ & $38.7 \%$ & $44.2 \%$ & 0.07 \\
\hline
\end{tabular}

a Adjusting for age, sex, diagnostic category and centre. ${ }^{\mathrm{b}}$ For subgroup of smokers; c for subgroup with overweight (BMI $\geq 25 \mathrm{~kg} / \mathrm{m}^{2}$ ); ${ }^{\mathrm{d}}$ for subgroup with history of hypertension; ${ }^{\mathrm{f}}$ for subgroup with history of hyperlipidaemia; ${ }^{\mathrm{f}}$ for total group

using lower cut-offs for blood pressure and total and LDL cholesterol given in more recent guidelines. There was no significant difference in the prevalence of current smoking between diabetic and non-diabetic patients. The prevalence of overall overweight and obesity, as well as abdominal obesity, was higher in diabetic than in non-diabetic patients. The prevalence of elevated blood pressure was higher in diabetic than in non-diabetic patients, although, as will be shown later, diabetic patients used blood-pressure-lowering drugs somewhat more frequently than non-diabetic patients. With lower cut-offs the prevalence of raised blood pressure was, however, similar in diabetic and non-diabetic patients. The prevalence of elevated total and LDL cholesterol was somewhat lower in diabetic than in non-diabetic patients. As will be shown later, almost two-thirds of diabetic and non-diabetic patients used lipid-lowering drugs. Yet among the users of lipid-lowering drugs, only $52.8 \%$ of diabetic and $51.3 \%$ of non-diabetic patients reached the LDL cholesterol goal of less than $3.0 \mathrm{mmol} / \mathrm{l}(p=0.02)$. Applying a lower LDL cholesterol goal $(<2.5 \mathrm{mmol} / \mathrm{l})$, the respective proportions were $32.4 \%$ vs $27.1 \%(p=0.0002)$.
Table 4 compares risk factor distributions in 4489 patients classified into four glycaemia categories: known diabetes, undiagnosed diabetes, impaired fasting glycaemia and normoglycaemia. The prevalence of smoking was lower in the known diabetes category than in other glycaemia categories. Patients in all IGR categories were more obese and had higher systolic blood pressure and triglycerides and lower HDL cholesterol than normoglycaemic patients. No consistent trends over the patient groups were observed in total and LDL cholesterol, but non-HDL cholesterol was higher in patients with impaired fasting glycaemia and undiagnosed diabetes than in normoglycaemic patients.

Lifestyle advice. Information collected at interview on lifestyle advice given to diabetic and non-diabetic patients to reduce their cardiovascular risk is summarised in Table 5. Personal advice to stop smoking had been given by a health worker somewhat more frequently to diabetic patients than to non-diabetic patients. The proportion of those who had attempted to stop smoking since the index event was, however, 
Table 6. Use of cardiovascular drugs in diabetic and non-diabetic patients in EUROASPIRE II

\begin{tabular}{lccc}
\hline & Diabetic $(n=1086)$ & Non-diabetic $(n=4464)$ & $p$ value $^{\mathrm{a}}$ \\
\hline Antiplatelet drugs & $83.4 \%$ & $86.4 \%$ & 0.08 \\
Beta-blockers & $62.1 \%$ & $63.0 \%$ & 0.84 \\
ACE-inhibitors & $49.2 \%$ & $35.3 \%$ & $<0.001$ \\
AII receptor antagonists & $5.2 \%$ & $3.2 \%$ & 0.008 \\
Calcium antagonists & $31.4 \%$ & $24.8 \%$ & 0.005 \\
Diuretics & $25.2 \%$ & $15.5 \%$ & $<0.001$ \\
Any BP-lowering drugs & $91.6 \%$ & $85.8 \%$ & $<0.001$ \\
Statins & $54.0 \%$ & $55.6 \%$ & 0.92 \\
Any lipid-lowering drugs & $61.5 \%$ & $60.6 \%$ & 0.27 \\
Anticoagulants & $7.0 \%$ & $6.5 \%$ & 0.64 \\
\hline
\end{tabular}

a Adjusting for age, sex, diagnostic category and centre. BP, blood pressure

Table 7. Prevalence of risk factors and use of cardiovascular drugs in diabetic and non-diabetic patients in EUROASPIRE I and EUROASPIRE II based on data from 9 centres participating in both surveys

\begin{tabular}{|c|c|c|c|c|c|c|}
\hline & \multicolumn{3}{|l|}{ Diabetic } & \multicolumn{3}{|c|}{ Non-diabetic } \\
\hline & $\begin{array}{l}\text { EA-I } \\
(n=641)\end{array}$ & $\begin{array}{l}\text { EA-II } \\
(n=740)\end{array}$ & Difference $(95 \% \mathrm{CI})$ & $\begin{array}{l}\text { EA-I } \\
(n=2928)\end{array}$ & $\begin{array}{l}\text { EA-II } \\
(n=2634)\end{array}$ & Difference $(95 \%$ CI) \\
\hline Current smoking & $14.8 \%$ & $18.1 \%$ & $3.3 \%(-0.7 \%$ to $7.2 \%)$ & $20.4 \%$ & $21.6 \%$ & $1.1 \%(-1.0 \%$ to $3.3 \%)$ \\
\hline Obesity ${ }^{\mathrm{a}}$ & $34.2 \%$ & $44.4 \%$ & $10.2 \%(5.0 \%$ to $15.2 \%)$ & $23.3 \%$ & $29.5 \%$ & $6.2 \%(3.9 \%$ to $8.5 \%)$ \\
\hline Raised blood pressure ${ }^{b}$ & $64.5 \%$ & $60.3 \%$ & $-4.2 \%(-9.3 \%$ to $0.9 \%)$ & $53.4 \%$ & $52.1 \%$ & $-1.3 \%(-4.0 \%$ to $1.3 \%)$ \\
\hline Beta-blockers & $52.0 \%$ & $66.0 \%$ & $14.0 \%(8.8 \%$ to $19.1 \%)$ & $54.0 \%$ & $66.5 \%$ & $12.5 \%(9.9 \%$ to $15.0 \%)$ \\
\hline ACE inhibitors & $43.2 \%$ & $52.0 \%$ & $8.8 \%(3.5 \%$ to $14.0 \%)$ & $26.5 \%$ & $40.0 \%$ & $13.4 \%(11.0 \%$ to $15.9 \%)$ \\
\hline Calcium antagonists & $40.1 \%$ & $32.0 \%$ & $-8.1 \%(-13.1 \%$ to $-3.0 \%)$ & $35.5 \%$ & $24.2 \%$ & $-11.3 \%(-13.7 \%$ to $-8.9 \%)$ \\
\hline Diuretics & $26.0 \%$ & $25.4 \%$ & $-0.6 \%(-5.3 \%$ to $4.0 \%)$ & $13.0 \%$ & $16.7 \%$ & $3.6 \%(1.8 \%$ to $5.5 \%)$ \\
\hline Any BP-lowering drugs & $90.0 \%$ & $93.6 \%$ & $3.6 \%(0.8 \%$ to $6.6 \%)$ & $82.8 \%$ & $88.9 \%$ & $6.1 \%(4.3 \%$ to $7.9 \%)$ \\
\hline Statins & $14.0 \%$ & $56.8 \%$ & $42.7 \%(38.1 \%$ to $47.0 \%)$ & $19.5 \%$ & $57.9 \%$ & $38.4 \%(36.0 \%$ to $40.8 \%)$ \\
\hline
\end{tabular}

BP, blood pressure EA-I, EUROASPIRE I; EA-II, EUROASPIRE II; a BMI $\geq 30 \mathrm{~kg} / \mathrm{m}^{2}$; b systolic BP $\geq 140$ and/or diastolic BP $\geq 90 \mathrm{~mm} \mathrm{Hg}$; ${ }^{\mathrm{c}}$ total cholesterol $\geq 5.0 \mathrm{mmol} / \mathrm{l}$

similar among diabetic and non-diabetic patients ( $80.5 \%$ vs $82.9 \%$ ). Among those who had attempted to stop, $14.4 \%$ of diabetic and $20.1 \%$ of non-diabetic patients had used nicotine replacement therapy $(p=0.15)$. Advice to reduce weight and to follow a diet aiming to lower blood pressure, when appropriate, had been given more often to diabetic than non-diabetic patients. About two-thirds of diabetic and non-diabetic patients with a history of hyperlipidaemia had received counselling on a cholesterol-lowering diet. Of all diabetic and non-diabetic patients, about two-thirds had received advice on exercise. Advice to participate in a cardiac rehabilitation programme was somewhat less frequent among diabetic than non-diabetic patients.

Use of cardiovascular drugs. The use of antiplatelet drugs, beta-blockers, statins, any lipid-lowering drugs and anticoagulants was almost similar in diabetic and non-diabetic patients (Table 6). The use of ACE-in- hibitors, AII receptor antagonists, calcium antagonists, diuretics and any blood-pressure-lowering drugs was more frequent among diabetic than non-diabetic patients. Insulin-treated diabetic patients used betablockers less frequently (55.4\% vs $64.6 \% ; p=0.006$ ), and the following more frequently than non-insulintreated patients: ACE-inhibitors $(55.4 \%$ vs $47.2 \%$; $p=0.001)$, calcium antagonists $(36.2 \%$ vs $29.5 \%$; $p=0.02)$ and diuretics $(34.8 \%$ vs $21.9 \% ; p<0.001)$. Considering all the eight different classes of prophylactic drugs listed in Table $6,23.3 \%$ of diabetic and $14.8 \%$ of non-diabetic patients used four or more of these drugs $(p<0.001)$.

\section{Comparison of EUROASPIRE I and II}

Table 7 presents the prevalence of risk factors and the use of cardiovascular drugs among diabetic and nondiabetic patients examined in EUROASPIRE I and II 
in the nine centres which participated in both surveys. Among diabetic and non-diabetic patients the prevalence of smoking had increased slightly and the prevalence of obesity had increased markedly. The prevalence of raised blood pressure remained almost unchanged, while the prevalence of elevated total cholesterol decreased markedly and by a similar margin in diabetic and non-diabetic patients.

The use of antiplatelet drugs, diuretics and anticoagulants remained virtually unchanged, whereas the use of beta-blockers increased and the use of calcium antagonists decreased by a similar amount in diabetic and non-diabetic patients. Although the proportion of patients using blood-pressure-lowering drugs was already very high in EUROASPIRE I, it was even higher in EUROASPIRE II among diabetic and nondiabetic patients. The use of lipid-lowering drugs among diabetic and non-diabetic patients was almost two times more frequent in EUROASPIRE II than in EUROASPIRE $I$ and this increase was due to a marked increase in the use of statins.

The interaction term between diabetic status and survey was not statistically significant for any of the outcome variables in the comparison of EUROASPIRE I and II. This indicates that the differences between the two surveys were similar in diabetic and non-diabetic patients.

\section{Discussion}

This study, based on EUROASPIRE I and II surveys, demonstrated a high prevalence of adverse lifestyle characteristics and modifiable risk factors in European diabetic and non-diabetic patients with CHD. In EUROASPIRE II about $20 \%$ of diabetic and non-diabetic patients continued to smoke, $43 \%$ of the diabetic patients and $29 \%$ of the non-diabetic patients were frankly obese $\left(B M I \geq 30 \mathrm{~kg} / \mathrm{m}^{2}\right), 57 \%$ of the diabetic patients and $49 \%$ of the non-diabetic patients had raised blood pressure (systolic blood pressure $\geq 140 \mathrm{~mm} \mathrm{Hg}$ and/or diastolic blood pressure $\geq 90 \mathrm{~mm}$ $\mathrm{Hg}$ ), and $55 \%$ of the diabetic patients and $59 \%$ of the non-diabetic patients had elevated total cholesterol $(\geq 5.0 \mathrm{mmol} / \mathrm{l})$.

A comparison of findings from EUROASPIRE I and II demonstrated some increase in the prevalence of smoking and a clear increase in the prevalence of obesity, no improvement in blood pressure control, but a clear improvement in cholesterol control, mainly explained by increased use of lipid-lowering drugs. As to the use of other proven prophylactic drugs, the use of antiplatelet drugs was already at an adequate level in EUROASPIRE I, and the use of beta-blockers and ACE-inhibitors increased between EUROASPIRE I and II, both in diabetic and in non-diabetic patients.

At $18 \%$ in EUROASPIRE I and $20 \%$ in EUROASPIRE II, the prevalence of previously diagnosed diabetes corresponded to the findings in other recent studies of patients with clinically established CHD [7, $8,9,10,11]$. Although it was not possible to classify the diabetic patients according to type of diabetes, the majority of them must have had Type 2 diabetes. In EUROASPIRE II, using FPG of $7.0 \mathrm{mmol} / 1$ or more as a criterion for undiagnosed diabetes, the total prevalence of diabetes rose to $28 \%$. Furthermore, when impaired fasting glycaemia (FPG $\geq 6.1 \mathrm{mmol} / \mathrm{l}$ but $<7.0 \mathrm{mmol} / \mathrm{l}$ ) was also included, almost half of the patients had IGR. This may, however, be an underestimate of the real situation, because the use of FPG as the only criterion, as compared with 2 -h plasma glucose in an OGTT, tends to underestimate the prevalence of undiagnosed diabetes and milder forms of IGR [37]. The potential importance of these undiagnosed glucose abnormalities with regard to the risk of recurrent CHD events is emphasised by our finding that in such patients the risk factor pattern resembled that observed in patients with previously diagnosed diabetes.

The most important limitation of EUROASPIRE surveys is that for practical reasons the patient populations from the participating countries were identified from geographically defined areas around academic cardiology centres and thus were not a representative sample of all CHD patients in each country. Independently of whether the results from the 15 countries participating in EUROASPIRE II, or only those from the nine countries participating in both surveys were considered, the findings of EUROASPIRE II were rather similar, suggesting that EUROASPIRE surveys have given a reasonably good overall picture about the status of secondary prevention of CHD in Europe. Nevertheless, as shown by the principal reports from EUROASPIRE I and II [31, 32], there were differences between countries in several aspects of preventive practice. An important strength of the EUROASPIRE surveys is that the interviews and risk factor measurements were carried out at a median interval of more than 1 year after the admission for an acute coronary event or revascularisation procedure, at a time when the patients were in a stable phase of their CHD and under their usual care. Thus the surveys provided information on the actual everyday practice of secondary prevention of CHD.

Although for practical reasons data collection had to be kept simple, our findings clearly indicate that dietary and other lifestyle aspects did not get enough attention, and thus important non-pharmacological opportunities of prevention were missed. The easier part of preventive care, prescription of prophylactic drugs, improved in terms of increasing proportions of patients receiving these drugs and in this respect the progress was rather similar among both diabetic and non-diabetic patients. Yet, considerable problems remained, particularly in achieving the treatment goals for blood pressure and cholesterol. 
In EUROASPIRE I and II about $90 \%$ of diabetic patients and almost as large a proportion of non-diabetic patients were taking one or several drugs with blood-pressure-lowering effect, although not always for the treatment of raised blood pressure but rather for the treatment of their CHD or heart failure. Yet, even with conservative blood pressure goal definitions only about one half of diabetic and non-diabetic patients reached those goals. Our surveys do not give any indication of how to explain this failure to achieve blood pressure control among CHD patients, but possible explanations include misunderstanding or negligence of treatment goals by physicians, too low drug dosages, and poor compliance on the part of the patients. Considering the recent recommendations on stricter blood pressure goals for diabetic patients (systolic blood pressure $<130 \mathrm{~mm} \mathrm{Hg}$ and diastolic blood pressure $<80 \mathrm{~mm} \mathrm{Hg}$ ) $[30,38]$, the treatment gap was even wider in diabetic patients with CHD.

As to cholesterol management, in EUROASPIRE II less than half of diabetic and non-diabetic patients had reached the conservative cholesterol goals (total cholesterol $<5.0 \mathrm{mmol} / \mathrm{l}$ or LDL cholesterol $<3.0 \mathrm{mmol} / \mathrm{l}$ ) of the 1998 Joint European Societies' guidelines [29]. The dosage of lipid-lowering drugs appeared to have often been inadequate, since only about one half of diabetic and non-diabetic patients taking lipid-lowering drugs had reached the LDL cholesterol goal of less than $3.0 \mathrm{mmol} / \mathrm{l}$, and only one-third the LDL cholesterol goal of less than $2.5 \mathrm{mmol} / \mathrm{l}$ recommended for patients with clinically established CHD in the 2003 revision of the Joint European Societies' guidelines [30].

Providing comprehensive care to diabetic patients with CHD is a challenging and complex task. Diabetic patients who are free of atherosclerotic disease are usually under the care of endocrinologists or family physicians for glycaemic control and monitoring for early detection of specific diabetic complications. However, when CHD is diagnosed, particularly if a myocardial infarction or other acute coronary event or coronary bypass surgery or percutaneous coronary intervention leads to hospital admission, attention to the cardiological problem becomes dominant, and the main responsibility in care tends to shift, at least for some time, to cardiologists, who may be less familiar with the management of diabetes and associated metabolic disorders. This may in part explain why our study demonstrated so poor glycaemic control and also poor management of obesity in diabetic patients with CHD. In the main area of interest for cardiologists, the use of cardiovascular drugs, the development was better and approximately similar in diabetic and non-diabetic patients. However, recognition of the particularly high risk of diabetic patients did not become evident in terms of a more aggressive approach in preventive care. To improve the comprehensive preventive care of diabetic patients with CHD, com- munication and cooperation between cardiologists and the physicians responsible for long-term care of these patients must be improved.

In conclusion, these European surveys of the practice of prevention in patients with CHD showed a high prevalence of adverse lifestyles and modifiable risk factors among both diabetic and non-diabetic patients, with a more adverse risk factor status among diabetic patients. The use of prophylactic drug therapies had improved, but was still far from optimal. The highrisk status of diabetic patients with CHD should lead to a more aggressive approach in their preventive care. Screening for undiagnosed diabetes and milder impairments of glucose regulation should become an integral part of the care of patients with clinically established CHD.

Acknowledgements. We thank the administrative staff, physicians, nurses, and other personnel of the hospitals in which the surveys were carried out. We also thank all the patients who participated. Unrestricted educational grants to the European Society of Cardiology were obtained from Merck, Sharp \& Dohme for EUROASPIRE I and from Astra Zeneca, BristolMyers Squibb, Merck, Sharp \& Dohme, and Pfizer for EUROASPIRE II.

\section{References}

1. Krolewski AS, Kosinski EJ, Warram JH et al. (1987) Magnitude and determinants of coronary artery disease in juvenile-onset, insulin-dependent diabetes mellitus. Am J Cardiol 59:750-755

2. Pyörälä K, Laakso M, Uusitupa M (1987) Diabetes and atherosclerosis: an epidemiologic view. Diabetes Metab Rev 3:463-524

3. Laakso M, Lehto S (1997) Epidemiology of macrovascular disease in diabetes. Diabetes Rev 5:294-315

4. Nathan DM, Meigs J, Singer DE (1997) The epidemiology of cardiovascular disease in type 2 diabetes mellitus: how sweet it is ... or is it? Lancet 350 [Suppl I]:SI4-SI9

5. Howard B, Rodriguez BL, Bennet PH et al. (2002) Prevention Conference VI. Diabetes and cardiovascular disease. Writing Group I: Epidemiology. Circulation 105:e132e137

6. Beckman JA, Creager MA, Libby P (2002) Diabetes and atherosclerosis: epidemiology, pathophysiology, and management. J Am Med Ass 287:2570-2581

7. Löwell H, König W, Engel S, Hörmann A, Keil U (2000) The impact of diabetes mellitus on survival after myocardial infarction: can it be modified by drug treatment? Results of a population-based myocardial infarction register follow-up study. Diabetologia 43:218-226

8. Malmberg K, Yusuf S, Gerstein HC et al. (2000) Impact of diabetes on long-term prognosis in patients with unstable angina and non-Q-wave myocardial infarction: results of the OASIS (Organization to Assess Strategies for Ischemic Syndromes) registry. Circulation 102:1014-1019

9. McGuire DK, Emanuelsson H, Granger CB et al. (2000) Influence of diabetes mellitus on clinical outcomes across the spectrum of acute coronary syndromes. Findings from the Gusto-IIb study. Gusto IIb Investigators. Eur Heart J $21: 1750-1758$ 
10. Mukamal KJ, Nesto RW, Cohen MC et al. (2001) Impact of diabetes on long-term survival after acute myocardial infarction: comparability or risk with prior myocardial infarction. Diabetes Care 24:1422-1427

11. Laskey WK, Selzer F, Vlachos HA et al. (2002) Comparison of in-hospital and one-year outcomes in patients with and without diabetes mellitus undergoing percutaneous catheter intervention (from the National Heart, Lung, and Blood Institute Dynamic Registry). Am J Cardiol 90:10621067

12. Norhammar A, Tenerz A, Nilsson G et al. (2002) Glucose metabolism in patients with acute myocardial infarction and no previous diagnosis of diabetes mellitus: a prospective study. Lancet 359:2140-2144

13. Herlitz J, Wognsen GB, Karlson BW et al. (2000) Mortality, mode of death and risk indicators for death during 5 years after coronary artery bypass grafting among patients with and without a history of diabetes mellitus. Coron Artery Dis 11:339-346

14. Pyörälä K, Pedersen T, Kjekshus J, Faergeman O, Olsson AG, Thorgeirsson G, the Scandinavian Simvastatin Survival Study (4S) Group (1997) Cholesterol lowering improves prognosis of diabetic patients with coronary heart disease. A subgroup analysis of the Scandinavian Simvastatin Survival Study (4S). Diabetes Care 20:614-620

15. Goldberg RB, Mellies MJ, Sacks FM et al., for the CARE Investigators (1998) Cardiovascular events and their reduction with pravastatin in diabetic and glucose-intolerant myocardial infarction survivors with average cholesterol levels. Subgroup analyses in the Cholesterol And Recurrent Events (CARE) trial. Circulation 98:2513-2519

16. Keech A, Colquhoun D, Best J et al. for the LIPID Study Group (2003) Secondary prevention of cardiovascular events with long-term pravastatin in patients with diabetes or impaired glucose tolerance. Diabetes Care 26:27132721

17. Rubins HB, Robins SJ, Collins D et al. (1999) Gemfibrozil for secondary prevention of coronary heart disease in men with low levels of high-density lipoprotein cholesterol. Veterans Affairs High-Density Lipoprotein Cholesterol Intervention Trial Study Group. N Engl J Med 341:410-418

18. Heart Protection Study Collaborative Group (2003) MRC/BHF Heart Protection Study of cholesterol lowering with simvastatin in 5963 people with diabetes. Lancet 361:2005-2016

19. Curb JD, Pressel SL, Cutler JA et al. (1996) Effect of diuretic-based anti-hypertensive treatment on cardiovascular disease risk in older diabetic patients with isolated systolic hypertension. J Am Med Ass 276:1886-1892

20. Hansson L, Zanchetti A, Carruthers SG et al. for the HOT Study Group (1998) Effects of intensive blood pressure lowering and low-dose aspirin in patients with hypertension: principal results of the Hypertension Optimal Treatment (HOT) randomised trial. Lancet 351:1755-1762

21. Tuomilehto J, Rastenyte D, Birkenhäger WH et al. (1999) Effects of calcium-channel blockade in older patients with diabetes and systolic hypertension. Systolic Hypertension in Europe Trial Investigators. N Engl J Med 340:677684

22. Antithrombotic Trialists' Collaboration (2002) Collaborative meta-analysis of randomised trials of antiplatelet therapy for prevention of death, myocardial infarction and stroke in high risk patients. Br Med J 324:71-86

23. Gundersen T, Kjekshus J (1983) Timolol treatment after myocardial infarction in diabetic patients. Diabetes Care 6:285-290
24. Moye LA, Pfeffer MA, Wun CC et al., for the SAVE Investigators (1994) Uniformity of captopril benefit in the SAVE subgroup analysis. Eur Heart J 15:2-8

25. Torp-Pedersen C, Kober L, Carlsen J, on behalf of the TRACE Study Group (1996) Angiotensin-converting enzyme inhibition after myocardial infarction: the Trandolapril Cardiac Evaluation study. Am Heart J 132:235243

26. Zuanetti G, Latini R, Maggioni M, Santoro L, Tognoni G, on behalf of the GISSI-3 Investigators (1997) Effect of the ACE-inhibitor lisinopril on mortality in diabetic patients with acute myocardial infarction: the data from the GISSI-3 study. Circulation 96:4239-4245

27. UK Prospective Diabetes Study (UKPDS) Group (1998) Intensive blood-glucose control with sulphonylureas or insulin compared with conventional treatment and risk of complications in patients with type 2 diabetes (UKPDS 33). Lancet 352:837-853

28. Pyörälä K, De Backer G, Graham I, Poole-Wilson PA, Wood DA, on behalf of the Task Force (1994) Prevention of coronary heart disease in clinical practice. Recommendations of the European Society of Cardiology, European Atherosclerosis Society and European Society of Hypertension. Eur Heart J 15:1300-1331

29. Wood D, De Backer G, Faergeman O, Graham I, Mancia $\mathrm{G}$, Pyörälä $\mathrm{K}$ together with members of the Task Force (1998) Prevention of coronary heart disease in clinical practice. Recommendations of the Second Joint Task of European and other Societies on Coronary Prevention. Eur Heart J 19:1434-1503

30. De Backer G, Ambrosioni E, Borch-Johnsen K et al. (2003) Executive summary. European guidelines on cardiovascular disease prevention in clinical practice. Third Task Force of European and other Societies on Cardiovascular Disease Prevention in Clinical Practice. Eur Heart J 24:1601-1610

31. EUROASPIRE Study Group (1997) EUROASPIRE. A European Society of Cardiology survey of secondary prevention of coronary heart disease: Principal results. Eur Heart J 18:1569-1582

32. EUROASPIRE II Study Group (2001) Lifestyle and risk factor management and use of drug therapies in coronary patients in 15 countries. Principal results from EUROASPIRE II Euro Heart Survey Programme. Eur Heart J 22:554-572

33. EUROASPIRE I and II Group (2001) Clinical reality of coronary prevention guidelines: a comparison of EUROASPIRE I and II in nine countries. Lancet 357:9951001

34. Report of a WHO Consultation (1999) Definition, diagnosis and classification of diabetes mellitus and its complications. Part 1: Diagnosis and classification of diabetes mellitus. World Health Organization (WHO/NCD/NCS/99.2), Geneva

35. Hsu JC (1996) Multiple comparisons: theory and methods. Chapman \& Hall, London

36. Newcombe RG (1998) Interval estimation for the difference between independent proportions: comparison of eleven methods. Stat Med 17:873-890

37. The DECODE-study group on behalf of the European Diabetes Epidemiology Group (1999) Is fasting glucose sufficient to define diabetes? Epidemiological data from 20 European studies. Diabetologia 42:647-654

38. American Diabetes Association (2003) Clinical practice recommendations 2003. Diabetes Care 26 [Suppl 1]:S1S 156 